\title{
Metabolic Engineering of Pseudomonas putida KT2440 to Produce Anthranilate from Glucose
}

OPEN ACCESS

Edited by:

Mattijs Julsing,

TU Dortmund University, Germany

Reviewed by:

Hermann J. Heipieper,

Helmholtz Centre for Environmental

Research - UFZ, Germany

Jin-Byung Park,

Ewha Womans University,

South Korea

${ }^{*}$ Correspondence:

Nick Wierckx

nick.wierckx@rwth-aachen.de

Specialty section:

This article was submitted to Microbiotechnology, Ecotoxicology

and Bioremediation,

a section of the journal

Frontiers in Microbiology

Received: 31 August 2015 Accepted: 09 November 2015 Published: 24 November 2015

Citation:

Kuepper J, Dickler J, Biggel M, Behnken S, Jäger G, Wierckx N and Blank LM (2015) Metabolic Engineering of Pseudomonas putida KT2440 to Produce Anthranilate from

Glucose. Front. Microbiol. 6:1310. doi: 10.3389/fmicb.2015.01310

\begin{abstract}
Jannis Kuepper ${ }^{1}$, Jasmin Dickler ${ }^{1}$, Michael Biggel ${ }^{1}$, Swantje Behnken², Gernot Jäger ${ }^{3}$, Nick Wierckx ${ }^{1 *}$ and Lars M. Blank ${ }^{1}$

1 Institute of Applied Microbiology (iAMB), Aachen Biology and Biotechnology (ABBt), Rheinisch-Westfälische Technische Hochschule Aachen University, Aachen, Germany, ${ }^{2}$ Bayer Technology Services GmbH, Leverkusen, Germany, ${ }^{3}$ Bayer MaterialScience AG, Leverkusen, Germany
\end{abstract}

The Pseudomonas putida KT2440 strain was engineered in order to produce anthranilate ( $\mathrm{OAB}$, ortho-aminobenzoate), a precursor of the aromatic amino acid tryptophan, from glucose as sole carbon source. To enable the production of the metabolic intermediate $\mathrm{OAB}$, the $\operatorname{trp} D C$ operon encoding an anthranilate phosphoribosyltransferase (TrpD) and an indole-3-glycerol phosphate synthase (TrpC), were deleted. In addition, the chorismate mutase (pheA) responsible for the conversion of chorismate over prephenate to phenylpyruvate was deleted in the background of the deletion of trpDC to circumvent a potential drain of precursor. To further increase the $\mathrm{OAB}$ production, a feedback insensitive version of 3-deoxy-D-arabinoheptulosonate-7-phosphate synthase encoded by the $\operatorname{aroG}^{D 146 N}$ gene and an anthranilate synthase (trp $E^{S 4 O F} G$ ) were overexpressed separately and simultaneously in the deletion mutants. With optimized production conditions in a tryptophan-limited fed-batch process a maximum of $1.54 \pm 0.3 \mathrm{~g} \mathrm{~L}^{-1}(11.23 \mathrm{mM}) \mathrm{OAB}$ was obtained with the best performing engineered $P$. putida KT2440 strain ( $P$. putida $\triangle$ trpDC pSEVA234_aroG $\left.{ }^{D 146 N} \_\operatorname{trp}^{S 40 F} \mathrm{G}\right)$.

\footnotetext{
Keywords: Pseudomonas putida KT2440, anthranilic acid, aromatic amino acid pathway, metabolic engineering, industrial biotechnology
}

\section{INTRODUCTION}

Anthranilate ( $\mathrm{AAB}$, ortho-aminobenzoate) is an aromatic acid used as a platform chemical for the production of food ingredients (Raffensperger and Vogt, 1961), dyes, perfumes (Wiklund and Bergman, 2006), crop protection compounds (Askham, 1992; Yadav and Krishnan, 1998; Chambers et al., 2013), pharmaceutical compounds (Bahia et al., 2011; Shafiq et al., 2011; Haynes et al., 2012; Gao et al., 2013; Loque and Weniger, 2013; Walsh et al., 2013), and plastics such as nylon (Sun et al., 2013). It is currently produced in energy intensive chemical processes from petroleumbased precursors, like phthalamic acid (Klipper and Gripper, 1981; Berg, 2009). Furthermore, the production of the precursors and the production of $\mathrm{OAB}$ accumulate toxic byproducts, such as hypochlorite which is used with molar equivalency to oAB (Berg, 2009). Thus, there is a strong motivation to find alternative routes to produce platform chemicals, such as $\mathrm{OAB}$, in green production processes from renewable resources in an environmental friendly way. In addition, the development and application of green production processes is accelerated by an environmental and political interest to be less dependent on fossil resources. 
Biocatalysis using living microbes as catalysts is a wellestablished alternative for the production of chemicals. The aromatic biosynthesis pathway and the derived compounds of the aromatic acids, such as $\mathrm{OAB}$, have been intensively studied in the last decades (Bongaerts et al., 2001; Ikeda, 2003; Kramer et al., 2003; Leuchtenberger et al., 2005; Pittard and Yang, 2008). Microbial production of oAB with engineered Escherichia coli strains was reported by Balderas-Hernandez et al. (2009) followed by further publications on oAB-derived compounds such as catechol and muconic acid (Sun et al., 2013; Averesch and Krömer, 2014; Balderas-Hernandez et al., 2014; Jaeger et al., 2015). To enable oAB production in E. coli, BalderasHernandez et al. $(2009,2014)$ inserted a point mutation in the oAB phosphoribosyl transferase domain $(\operatorname{tr} p D)$, whereas Sun et al. (2013) used the Keio collection deletion strain E. coli BW25113 $\Delta$ trp::kan to prevent the conversion of oAB to tryptophan. Additional targets to increase the production of $\mathrm{oAB}$ in $E$. coli, for example the overexpression of feedback insensitive variants of the 3-deoxy-D-arabino-heptulosonate-7phosphate (DAHP) synthase and the anthranilate synthase unit $\left(\operatorname{trp} E^{S 40 F} G\right)$ were investigated. A maximum titer of $14 \mathrm{~g} \mathrm{~L}^{-1} \mathrm{oAB}$ was reported growing the engineered strains in complex medium containing $30 \mathrm{~g} \mathrm{~L}^{-1}$ yeast extract (Balderas-Hernandez et al., 2009).

Here, we present the first attempt of microbial production of oAB from glucose as sole carbon source with an engineered $P$ seudomonas putida KT2440 strain. Due to its versatile metabolism and low nutritional requirements $P$. putida is an efficient production strain for various industrial relevant products (Tiso et al., 2014). In addition its high biomass yield, high growth rate, and low maintenance demand fulfill the rigorous demands of industrial biotechnology (PobleteCastro et al., 2012). A broad portfolio of P. putida biocatalysts for bulk chemicals such as phenol (Wierckx et al., 2005), p-hydroxystyrene (Verhoef et al., 2009), p-hydroxybenzoate (Verhoef et al., 2007), rhamnolipids (Wittgens et al., 2011), polyhydroxyalkanoates (PHA; Wang et al., 2011), and (S)styrene oxide (Blank et al., 2008) demonstrate the great potential of this species as a flexible cell factory for the production of chemicals in industrial biotechnology. In addition, $P$. putida strains have the capability to withstand various chemical stresses such as a second phase of toluene, octanol, or styrene (Heipieper and de Bont, 1994; Dominguez-Cuevas et al., 2006; Blank et al., 2008), as well as oxidative stress (Chavarria et al., 2013) and reduced water activity (Hallsworth et al., 2003), and thus providing a promising and versatile chassis for the production of toxic compounds such as oAB.

To ensure industrially relevant $\mathrm{OAB}$ production conditions a full, markerless deletion of $\operatorname{trpDC}$ was performed in P. putida, facilitated by the fact that in contrast to $E$. coli the $\operatorname{trpEG}$ and $\operatorname{trpDC}$ genes are encoded by separate open reading frames. Additionally the production of $\mathrm{OAB}$ was realized on glucose as sole carbon source, avoiding the addition of high amounts of complex media components such as yeast extract. A maximum titer of $1.54 \pm 0.3 \mathrm{~g} \mathrm{~L}^{-1}(11.23 \mathrm{mM})$ oAB was obtained with the best performing engineered $P$. putida KT2440 strain (P. putida $\triangle \operatorname{trpDC}$ pSEVA234_aroG $\left.{ }^{D 146 N} \_\operatorname{trp} E^{S 40 F} G\right)$ in tryptophan-limited fed-batch fermentations with glucose as sole carbon source.

\section{MATERIALS AND METHODS}

\section{Strains and Plasmids}

The deletion of $\operatorname{trpDC}$ and pheA were performed by a clean and markerless deletion method described by Martinez-Garcia and de Lorenzo (2011) resulting in two knock out strains P. putida KT2440 trpDC and P. putida KT2440 trpDC pheA. To obtain the knockout vectors pEMG_ $\operatorname{trp} D C$ and $\mathrm{pEMG} \_\Delta p h e A$ were obtained via a standard restriction and ligation approach and were transformed into chemical competent E. coli $\mathrm{DH} 5 \alpha$ (according to Choi et al., 2006) via electroporation. The 800bp flanks upstream (TS1) and downstream (TS2) of the gene of interest ( $\operatorname{trpDC}$ and $p h e A$ ) were amplified by PCR using a Pfu polymerase (New England Biolabs) with the primers listed in Table 1.

TS1 and TS2 were fused in a SOEing-PCR using Pfu polymerase according to Horton (1995). The backbone (pEMG) and the fused SOEing-PCR fragment were digested with $\mathrm{BamHI}$ and EcoRI for the deletion of trpDC and with BamHI and SbfI for the deletion of pheA. The digested backbones, TS1, and TS2 were purified (High Pure PCR Product Purification Kit, Roche), ligated with a T4 DNA ligase (Thermo Fisher Scientific) and transformed into chemical competent E. coli DH5 $\alpha$ (according to Choi et al., 2006) via electroporation. Constructs were verified by restriction analysis and sequencing, resulting in pEMG_strpDC and pEMG_spheA. Genome integration of the knockout constructs into the $P$. putida strains was performed via tri-parental mating according to Ditta et al. (1980) using E. coli HB101 pRK2013 as the helper strain and facilitated as

TABLE 1 | Primer sequences.

\begin{tabular}{|c|c|c|}
\hline Name & DNA sequence & $T_{\mathrm{m}}\left({ }^{\circ} \mathrm{C}\right)$ \\
\hline \multicolumn{3}{|c|}{ TS1 $\Delta$ trpDC } \\
\hline JK034f & $\begin{array}{l}\text { agggataacagggtaatctgaatTCGTCAGCAA } \\
\text { ACTCTTGATG }\end{array}$ & 61.6 \\
\hline JK035r & tttgactcgagGTTCGATCCTTAACGGCG & 61.6 \\
\hline \multicolumn{3}{|c|}{ TS2 $\Delta \operatorname{trpDC}$} \\
\hline JK036f & $\begin{array}{l}\text { aggatcgaacctcgagTCAAATGAAGCCGG } \\
\text { CGTT }\end{array}$ & 66.1 \\
\hline JK037r & $\begin{array}{l}\text { cctgcaggtcgactctagaggatccTCGAACCAA } \\
\text { GGTGCTACCG }\end{array}$ & 66.1 \\
\hline \multicolumn{3}{|c|}{ TS1 $\Delta$ pheA } \\
\hline JK038f & $\begin{array}{l}\text { attcgagctcggtacccggggatccACTACATCG } \\
\text { AAACCGGCATC }\end{array}$ & 61.8 \\
\hline JK039r & $\begin{array}{l}\text { ctgaactcgagTCAGCCATGCTCC } \\
\text { TTCTC }\end{array}$ & 61.8 \\
\hline \multicolumn{3}{|c|}{ TS2 $\Delta$ pheA } \\
\hline JKO4Of & $\begin{array}{l}\text { gcatggctgactcgagTTCAGGGGCCTTGG } \\
\text { GGCT }\end{array}$ & 70.2 \\
\hline JK041r & $\begin{array}{l}\text { tagaagcttgcatgcctgcaggCAGTGAGTCGA } \\
\text { CCAGGCCAAAG }\end{array}$ & 70.2 \\
\hline
\end{tabular}


TABLE 2 | Summary of plasmids and strains used in this study.

\begin{tabular}{|c|c|c|}
\hline & Description & Reference \\
\hline \multicolumn{3}{|l|}{ Plasmids } \\
\hline pEMG & $\mathrm{Km}^{\mathrm{R}}$, oriR6K, lacZa with two flanking I-Scel sites & Martinez-Garcia and de Lorenzo, 2011 \\
\hline pSEVA234 & $\mathrm{Km}^{\mathrm{R}}$, oriBBR1, lacla-Ptrc & Silva-Rocha et al., 2013 \\
\hline pSW-I & $A p^{R}$, oriRK2, xylS, Pm $\rightarrow$-Scel & Martinez-Garcia and de Lorenzo, 2011 \\
\hline pRK2013 & $\mathrm{Km}^{\mathrm{R}}$, oriRK2, oriColE1 & Figurski et al., 1979 \\
\hline pEMG_strpDC & $\operatorname{trp} D C$ deletion plasmid & This work \\
\hline pEMG_spheA & pheA deletion plasmid & This work \\
\hline pSEVA234_trpE $E^{S 4 O F} G$ & $\operatorname{trp} E^{S 40 F} \mathrm{G}$ expression plasmid & This work \\
\hline pSEVA234_aroG ${ }^{D 146 N}$ & aroG ${ }^{D 146 N}$ expression plasmid & This work \\
\hline pSEVA234_aroG ${ }^{D 146 N} \operatorname{trp}^{S 40 F} \mathrm{G}$ & $\operatorname{aroG}^{D 146 N}$-trpE $E^{S 4 O F} G$ expression plasmid & This work \\
\hline \multicolumn{3}{|l|}{ Strain } \\
\hline Psuedomonas putida KT2440 & $\begin{array}{l}\text { Wild-type strain derived of } P \text {. putida mt- } 2 \text { cured of the } \\
\text { pWWO plasmid }\end{array}$ & Bagdasarian et al., 1981 \\
\hline Escherichia coli DH5 $\alpha$ & $\begin{array}{l}\text { supE44, DlacU169 (f80 lacZDM15), hsdR17 (rk-mk+), } \\
\text { recA1, endA1, thi1, gyrA, relA }\end{array}$ & Hanahan, 1985 \\
\hline E. coli DH5 $\alpha \lambda$ pir & $\lambda$ pir phage lysogen of $\mathrm{DH} 5 \alpha$ & De Lorenzo Lab collection \\
\hline E. coli HB101 pRK2013 & $\begin{array}{l}\mathrm{Sm}^{\mathrm{R}} \text {, hsdR-M+, pro, leu, thi, recA, } \mathrm{Km}^{\mathrm{R}} \text {, oriRK2, } \\
\text { oriColE1 }\end{array}$ & Figurski et al., 1979 \\
\hline E. coli DH5 $\alpha$ גpir pEMG & Plasmid carrier strain & Martinez-Garcia and de Lorenzo, 2011 \\
\hline E. coli DH5 $\alpha \lambda$ pir pSW-I & Plasmid carrier strain & Martinez-Garcia and de Lorenzo, 2011 \\
\hline E. coli DH5 $\alpha \lambda$ pir pEMG_ $\Delta$ trpDC & Plasmid carrier strain & This work \\
\hline 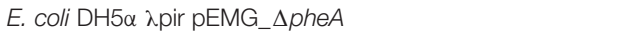 & Plasmid carrier strain & This work \\
\hline E. coli DH5 $\alpha$ pSEVA234_trpE $E^{S 40 F} G$ & Plasmid carrier strain & This work \\
\hline E. coli DH5 $\alpha$ pSEVA234_aroG ${ }^{D 146 N}$ & Plasmid carrier strain & This work \\
\hline E. coli DH5 $\alpha$ pSEVA234_aroG ${ }^{D 146 N}$ trp $^{S 40 F} G$ & Plasmid carrier strain & This work \\
\hline P. putida KT2440 pSEVA234_trpE ${ }^{S 40 F} G$ & $\mathrm{OAB}$ production strain & This work \\
\hline P. putida KT2440 pSEVA234_aroG ${ }^{D 146 N}$ & $\mathrm{OAB}$ production strain & This work \\
\hline P. putida KT2440 pSEVA234_aroG ${ }^{D 146 N}$ trpE $^{S 4 O F} G$ & $\mathrm{OAB}$ production strain & This work \\
\hline P. putida KT2440 $\Delta \operatorname{trpDC}$ & oAB production strain & This work \\
\hline P. putida KT2440 $\Delta$ trpDC pSEVA234_trpE $E^{S 40 F} G$ & $\mathrm{OAB}$ production strain & This work \\
\hline P. putida KT2440 $\Delta \operatorname{trpDC}$ pSEVA234_aroG ${ }^{D 146 N}$ & $\mathrm{OAB}$ production strain & This work \\
\hline P. putida KT2440 $\Delta \operatorname{trpDC}$ pSEVA234_aroG ${ }^{D 146 N}$ trpE $^{S 40 F} \mathrm{G}$ & $\mathrm{OAB}$ production strain & This work \\
\hline P. putida KT2440 $\Delta$ trpDC $\Delta p h e A$ & $\mathrm{OAB}$ production strain & This work \\
\hline P. putida KT2440 $\Delta$ trpDC $\Delta$ pheA pSEVA234_trpE $E^{S 40 F} G$ & $\mathrm{OAB}$ production strain & This work \\
\hline P. putida KT2440 $\Delta$ trpDC $\Delta$ pheA pSEVA234_aroG ${ }^{D 146 N}$ & OAB production strain & This work \\
\hline $\begin{array}{l}\text { P. putida KT2440 } \Delta \operatorname{trpDC} \Delta p h e A \\
\text { pSEVA234_aroG }{ }^{D 146 N} \_\operatorname{trp} E^{S 4 O F} G\end{array}$ & $\mathrm{OAB}$ production strain & This work \\
\hline
\end{tabular}

described in Zobel et al. (2015) where the three mating strains were streaked one above the other on a LB plate. The resulting strains were transformed with the plasmid expressing the ISce-I endonuclease (pSW-I; according to Choi et al., 2006). Induction with 3-methylbenzoate was omitted due to the leaky expression of the ISce-I nuclease. Successful construction of the knockout strains was verified via restriction, PCR and Sanger sequencing.

The feedback insensitive overexpression constructs were obtained via a standard restriction and ligation approach as described above using BamHI and EcoRI for aroG $G^{D 146 N}$ and BamHI for $\operatorname{trp} E^{S 40 F} G$. pSEVA234 (Silva-Rocha et al., 2013), which contains an IPTG inducible lacI ${ }^{Q}-P_{\text {trc }}$ expression system, was used as backbone. The genes $\operatorname{aroG}^{D 146 N}$ (Kikuchi et al., 1997; Albermann et al., 2014) and $\operatorname{trp} E^{S 40 F} G$ (Kwak et al., 1999) were synthesized at Eurofins Genomics. A summary of the used and constructed plasmids and of the engineered strains is shown in Table 2. All primers were purchased at Eurofins Genomics and all restriction enzymes at Thermo Fisher Scientific.

\section{Cultivation Conditions}

For cloning and maintenance processes, E. coli strains and $P$. putida strains were cultivated at 37 and $30^{\circ} \mathrm{C}$, respectively, in LB medium supplemented with or without kanamycin (50 $\mathrm{mg} \mathrm{L}^{-1}$ ) or ampicillin $\left(100 \mathrm{mg} \mathrm{L}^{-1}\right.$ for E. coli and $500 \mathrm{mg} \mathrm{L}^{-1}$ for P. putida), and/or with $1.5 \%$ (w/v) agar as needed.

Auxotrophies (tryptophan and phenylalanine) of the gene deletion mutants were verified on solid mineral medium plates (Wierckx et al., 2005) with 1.5\% (w/v) agar, $20 \mathrm{mM}$ glucose with and without $1 \mathrm{mM}$ tryptophan, and/or $1 \mathrm{mM}$ phenylalanine supplementation. Alternatively $1 \mathrm{mM}$ phenylpyruvate was used instead of phenylalanine. 
Batch-wise $\mathrm{oAB}$ production was performed in $500 \mathrm{~mL}$ shake flasks at $30^{\circ} \mathrm{C}$ and $200 \mathrm{rpm}$ in $50 \mathrm{~mL}$ mineral medium as described in Wierckx et al. (2005) with $20 \mathrm{mM}$ glucose (unless stated differently), $50 \mathrm{mg} \mathrm{L}{ }^{-1}$ kanamycin, and $1 \mathrm{mM} \mathrm{IPTG,}$ supplemented with either 0.1 or $0.05 \mathrm{mM}$ tryptophan and $1 \mathrm{mM}$ phenlypyruvate for the $\Delta$ pheA strains. Two additional $20 \mathrm{mM}$ glucose pulses were added after 10 and $24 \mathrm{~h}$ unless stated differently.

Tryptophan-limited fed-batch conditions were realized in controlled bioreactors (BioFlo 110 or BioFlo 115, Eppendorf / New Brunswick Scientific) with a starting volume of $400 \mathrm{~mL}$. The initial fermentation medium consisted of mineral medium with $50 \mathrm{mM}$ glucose, a twofold phosphate buffer concentration, a threefold $\left(\mathrm{NH}_{4}\right)_{2} \mathrm{SO}_{4}$ concentration, a onefold trace element solution, $1 \mathrm{mM}$ IPTG, $50 \mathrm{mM}$ kanamycin, and $0.1 \mathrm{mM}$ tryptophan. After the initial batch phase, the feed was switched on at a rate of $2 \mathrm{~mL} \mathrm{~h}^{-1}$ consisting of a mixed solution of $1 \mathrm{M}$ glucose and $0.5 \mathrm{mM}$ (glucose to tryptophan molar ratio of 2,000:1) or $1 \mathrm{mM}$ (glucose to tryptophan molar ratio of 1,000:1) tryptophan. To compensate for the increasing biomass concentrations the $1 \mathrm{mM}$ tryptophan feed was increased to $6 \mathrm{~mL} \mathrm{~h}^{-1}$. The fermentations were performed at $30^{\circ} \mathrm{C}$, with $500-$ $1,200 \mathrm{rpm}$ agitation $\left(\mathrm{dO}_{2}\right.$ regulated agitation cascade with a lower limit of $35 \%$ ), with $1 \mathrm{vvm}$ headspace aeration of compressed air. The $\mathrm{pH}$ was regulated to $\mathrm{pH}=7$ with $2 \mathrm{M} \mathrm{KOH}$ and $4 \mathrm{M} \mathrm{H}_{2} \mathrm{SO}_{4}$.

\section{Analytics}

The biomass concentration was measured with a spectrophotometer (Ultrospec 10, GE Healthcare Life Sciences). In this device the $\mathrm{OD}_{600}$ correlates to cell dry weight (CDW): 1 $\mathrm{OD}_{600}=0.505 \mathrm{~g}_{\mathrm{CDW} \mathrm{L}} \mathrm{L}^{-1}$. The samples taken during cultivation were centrifuged at $13,300 \mathrm{rpm}$ for $3 \mathrm{~min}$ and stored at $-20^{\circ} \mathrm{C}$ for further analysis. To follow the consumption of the glucose and derivatives (gluconate and 2-ketogluconate) by the P. putida KT2440 strains, a Beckman HPLC equipped with an organic acid resin column (polystyrol-divinylbenzol copolymer, PS-DVB: $300 \times 8.0 \mathrm{~mm}$, CS-Chromatographie) was used with $5 \mathrm{mM}$ $\mathrm{H}_{2} \mathrm{SO}_{4}$ as eluent at a flow of $0.8 \mathrm{~mL} \mathrm{~h}{ }^{-1}$ for $11 \mathrm{~min}$ at $75^{\circ} \mathrm{C}$. Detection was realized with an UV detector at a wavelength of $210 \mathrm{~nm}$ and a RI detector. The $\mathrm{OAB}$ production was analyzed with a reverse phase column (LiChrosorb $100 \mathrm{RP}-18,250 \times 4 \mathrm{~mm}$, Merck), at a flow of $1.2 \mathrm{~mL} \mathrm{~h}^{-1}$ [pump gradient of $\mathrm{H}_{2} \mathrm{O}+0.1 \%$ TFA (pump A) and of $\mathrm{MeOH}$ (pump B): 0-2 min 90\% A, 212 min gradient $0-90 \%$ A, 12-14 min 0\% A, 14-15 min gradient 0-90\% A, and 15-16 min $90 \% \mathrm{~A}$ ] at $30^{\circ} \mathrm{C}$. Detection was realized with an UV detector at a wavelength of $257 \mathrm{~nm}$ and a RI detector.

\section{RESULTS AND DISCUSSION}

\section{Metabolic Engineering of $\mathrm{OAB}$ Production Strains}

In order to establish oAB production in $P$. putida, the $\operatorname{trpDC}$ and pheA genes were knocked out using the I-SceIbased pEMG system (Martinez-Garcia and de Lorenzo, 2011). Disruption of the $\operatorname{trpDC}$ genes, which encode an anthranilate phosphoribosyltransferase (TrpD) and an indole-3-glycerol

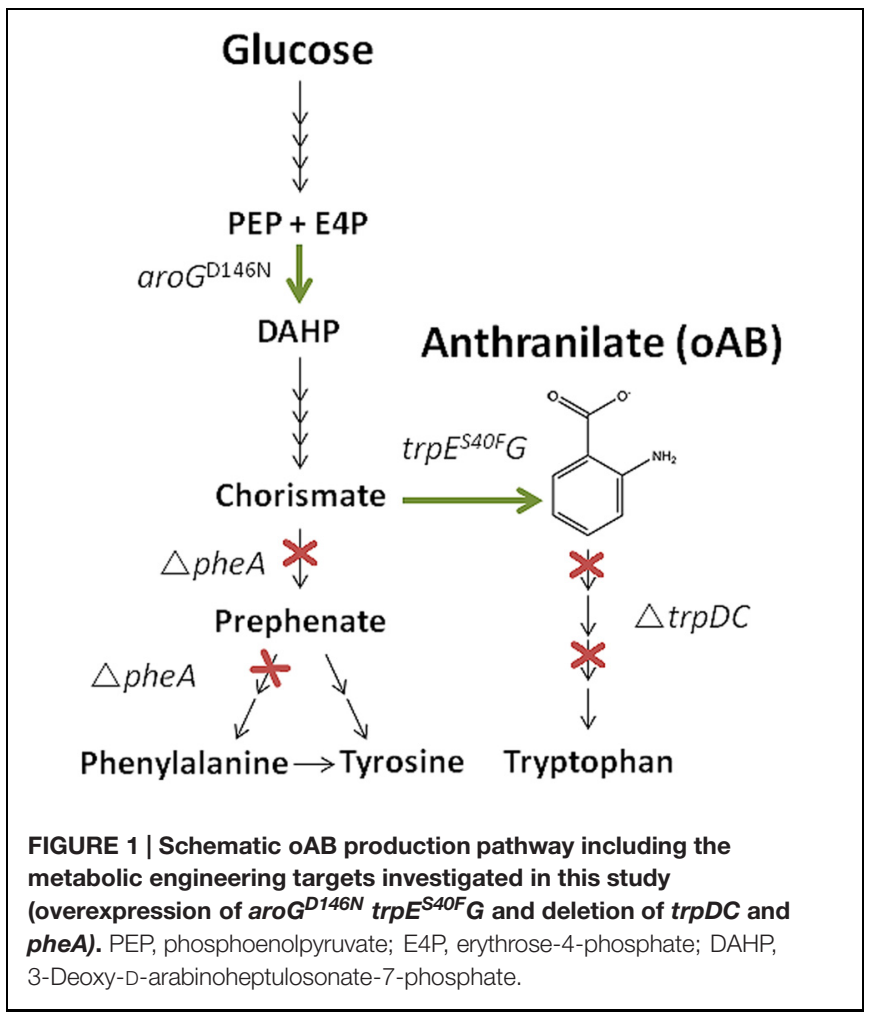

phosphate synthase (TrpC), leads to a tryptophan auxotrophy and enables the accumulation of oAB (Figure 1). Disruption of the pheA gene, which encodes a bifunctional chorismate mutase/prephenate dehydratase enzyme responsible for the first two steps of the synthesis of phenylalanine and tyrosine, possibly increases the metabolic flux toward $\mathrm{OAB}$ by reducing the drain on its primary precursor chorismate (Zhao et al., 2011). Contrary to other established production hosts, the pheA deletion only requires phenylalanine to complement growth since $P$. putida can convert phenylalanine to tyrosine (Molina-Henares et al., 2009). The corresponding auxotrophies were verified on mineral medium plates (Table 3 ).

TABLE 3 | Auxotrophy supplementation of $P$. putida KT2440 $\triangle$ trpDC and $\triangle p h e A$ knockouts.

\begin{tabular}{llc}
\hline Name & Supplementation & Growth \\
\hline P. putida KT2440 & None & + \\
& $\operatorname{trp}$ & + \\
& phe & + \\
P. putida KT2440 $\Delta$ trpDC & $\operatorname{trp}+$ phe & + \\
P. putida KT2440 $\Delta \operatorname{trp} D C \Delta$ pheA & None & - \\
& Trp & + \\
& None & - \\
& Trp & + \\
& $\operatorname{trp}+$ phe & + \\
\hline
\end{tabular}

a Mineral medium plates with $20 \mathrm{mM}$ glucose supplemented with $1 \mathrm{mM}$ tryptophan (trp), phenylalanine (phe), or phenylpyruvate (pp). 


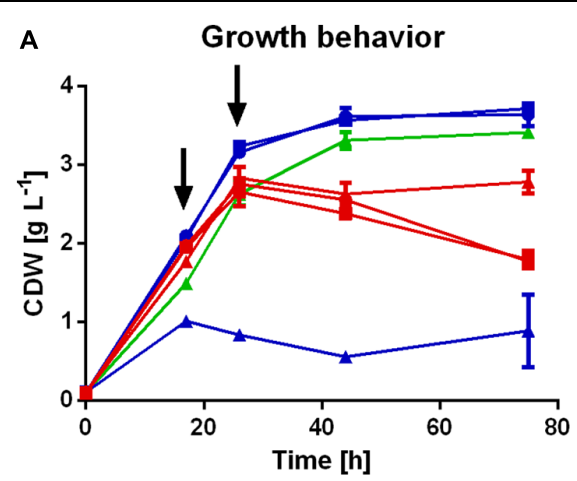

B

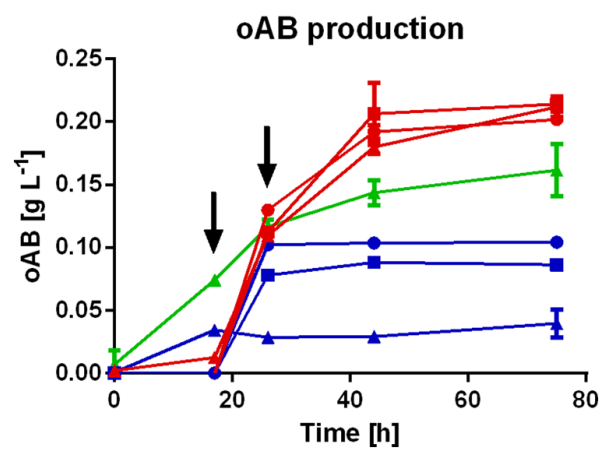

FIGURE 2 | OAB production profiles of various $P$. putida KT2440 strains in shake flasks. Biomass growth (A) and $\mathrm{AB}$ production $(\mathbf{B})$ of the following Pseudomonas putida KT2440 strains in an initial screening experiment:

•, $\Delta$ trpDC pSEVA234_trpE ${ }^{S 4 O F}$ G; • $\Delta \operatorname{trpDC}$ pSEVA234_aroG ${ }^{D 146 N}$;

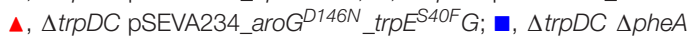

pSEVA234_trpE ${ }^{S 40 F} \mathrm{G} ; \bullet, \Delta \operatorname{trpDC} \triangle \mathrm{pheA}$ pSEVA234_aroG ${ }^{D 146 N}$;

ム, $\Delta \operatorname{trpDC} \triangle$ pheA pSEVA234_aroG ${ }^{D 146 N} \operatorname{trpE}^{S 40 F} \mathrm{G} ; \mathbf{\Delta}$,

pSEVA234_aroG ${ }^{D 146 N} \operatorname{trp}^{S 4 O F} \mathrm{G}$. All cultures were performed in mineral medium with $20 \mathrm{mM}$ initial glucose concentration and addition of tryptophan and/or phenylpyruvate as described above. The arrows indicate the addition of glucose to a concentration of $20 \mathrm{mM}$.

In the knockout process, the deletion of pheA could only be obtained by supplementation with phenylpyruvate. The final step of the knockout procedure (induction of the double strand break) should theoretically yield a one-to-one ratio of wildtype to knockout allele. However, selection on LB- or LB medium with phenylalanine resulted in the wildtype allele only, even after testing $>1,000$ colonies either by PCR or by screening for phenylalanine auxotrophy. This may be attributed to the ability of $P$. putida to degrade phenylalanine and tyrosine. Possibly, supplementation with phenylpyruvate instead of phenylalanine reduced the induction of genes encoding the phenylalanine and tyrosine catabolic pathway (Arias-Barrau et al., 2004), facilitating the successful isolation of the knockout strain. The final pheA knockout auxotroph could be complemented with phenylalanine in mineral medium. However, in this case a severe negative effect on the fitness of the mutant caused by the deletion of pheA was observed. Therefore, all subsequent $\Delta p h e A$ complementation were done with phenylpyruvate.

To further optimize the production of oAB in P. putida, feedback insensitive pSEVA234-based (Silva-Rocha et al., 2013)

\section{P. putida $\triangle \operatorname{trpDC} \operatorname{trp} E G+0,1 \mathrm{mM}$ Trp}

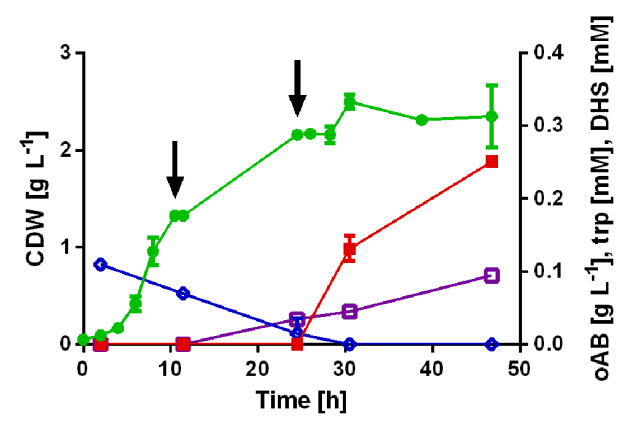

FIGURE 3 | Detailed profiles of $\bigcirc$, cell dry weight; $\square$, oAB; $\diamond$, tryptophan (trp); $\square$, dehydroshikimate (DHS) concentrations of the best selected strain $P$. putida KT2440 $\Delta$ trpDC pSEVA234_trpE ${ }^{S 40 F} G$ generated under slightly optimized production conditions. All cultures were performed in mineral medium with $20 \mathrm{mM}$ initial glucose concentration and addition of tryptophan and/or phenylpyruvate as described above. The arrows indicate the addition of glucose to a concentration of $20 \mathrm{mM}$.

overexpression constructs for $\operatorname{trp}^{S 40 F} G$ and $\operatorname{aro} G^{D 146 N}$, or both genes in one operon structure, were transformed to the respective mutants under the IPTG-inducible $\mathrm{LacI}^{Q_{-}} \mathrm{P}_{\text {trc }}$ system. These genes encode feedback insensitive variants of anthranilate synthase and 3-deoxy-D-arabino-heptulosonate-7phosphate (DHAP) synthase, respectively, and are known to enhance $\mathrm{OAB}$ production in E. coli (Balderas-Hernandez et al., 2009, 2014; Sun et al., 2013). Figure 1 shows the exemplarily oAB production pathway and gives on overview over the metabolic engineering targets investigated in this study.

\section{Evaluation of $\mathrm{OAB}$ Production Strains in Shake Flasks}

The P. putida strains engineered for the production of oAB (listed in Table 2) were initially assessed in shake flasks (Figures 2A,B) and under slightly optimized production conditions a maximum titer of $0.25 \pm 0.004 \mathrm{~g} \mathrm{~L}^{-1}(1.83 \mathrm{mM})$ $\mathrm{oAB}$ with glucose as sole carbon source was achieved (Figure 3). The three $\triangle \operatorname{trpDC}$ strains bearing either $\operatorname{tr} p E^{S 40 F} G$, aro $G^{D 146 N}$ or both, have shown no significant differences in maximal $\mathrm{oAB}$ titers, although the onset of production was earlier in the P. putida KT2440 $\Delta \operatorname{trpDC}$ pSEVA234_aroG ${ }^{D 146 N} \_\operatorname{tr} p E^{S 40 F} G$. Interestingly, $\mathrm{OAB}$ production was also observed with $P$. putida KT2440 pSEVA234_aroG $G^{D 146 N} \_\operatorname{trp} E^{S 40 F} G$ (without trpDC deletion) while no tryptophan was secreted, although the maximal titer was lower than that of the $\triangle \operatorname{trpDC}$ strains. This can be explained by the transcriptional repression of trp genes by tryptophan through the TrpR repressor (Maurer and Crawford, 1971; Wierckx et al., 2008). Likely, an increase of intracellular tryptophan caused repression of the native trp genes, leading to anthranilate accumulation due to the heterologous expression of $\operatorname{trp} E^{S 40 F} G$.

A strong connection was observed between tryptophan limitation and $\mathrm{OAB}$ production. When supplementing the auxotrophic strains with tryptophan the $\mathrm{OAB}$ production was 

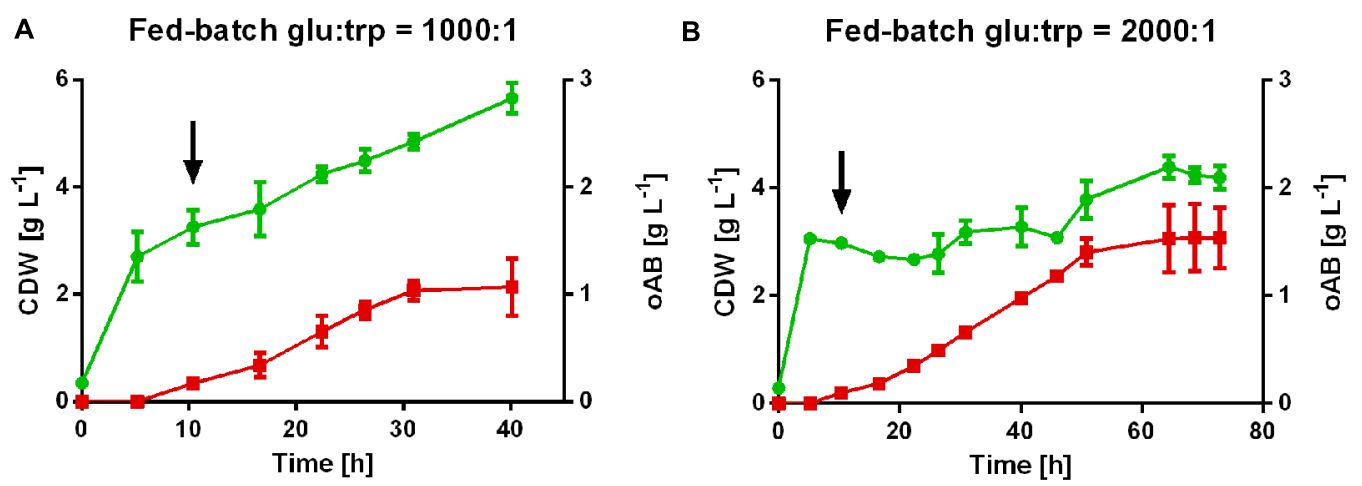

FIGURE 4 | Tryptophan-limited fed-batch cultures of $P$. putida KT2440 $\triangle \operatorname{trpDC}$ pSEVA234_aroG ${ }^{D 146 N}$ trpE $^{\mathrm{S} 40 F} \mathrm{G}$ in controlled bioreactors with different feeding approaches. (A) Feed molar ratio of glucose to tryptophan 1,000:1. (B) Feed molar ratio of glucose-to-tryptophan 2,000:1. •, cell dry weight; a, OAB concentration. The arrows indicate the start of the feed after the initial batch phase.

induced only upon depletion of the added tryptophan. Strains expressing both aroG $G^{D 146 N}$ and $\operatorname{trp} E^{S 40 F} G$ produced oAB at earlier time points compared to strains with only one of the feedback insensitive genes, indicating somewhat alleviated feedback insensitivity to tryptophan (Figure 2). With the nonauxotrophic $P$. putida pSEVA234_aro $G^{D 146 N} \_\operatorname{trp} E^{S 40 F} G$, where a supplementation with tryptophan was not required, oAB titers were significantly higher at earlier time points, indicating no inhibition by tryptophan. However, the final oAB titers were $34 \%$ lower compared to the P. putida $\triangle \operatorname{trpDC}$ strains, indicating a positive effect of the deletion of $\operatorname{trpDC}$.

As indicated above, a clear negative effect of the deletion of pheA on the growth behavior was observed. Whereas P. putida KT2440 pSEVA234_trpE ${ }^{S 40 F} G$ and $P$. putida KT2440 $\Delta$ trpDC pSEVA234_trpE ${ }^{S 40 F} G$ were able to grow up to $3.6 \mathrm{~g} \mathrm{~L}^{-1}$ CDW and $2.4 \mathrm{~g} \mathrm{~L}^{-1} \mathrm{CDW}$, respectively; P.putida KT2440 $\triangle \operatorname{trpDC} \triangle p h e A$ pSEVA234_trp $E^{S 40 F} G$ only reached a maximal CDW concentration of $1.4 \mathrm{~g} \mathrm{~L}^{-1}$ after 10 hours when supplemented with $1 \mathrm{mM}$ phenylpyruvate. Further addition of glucose and/or tryptophan could neither initiate growth to higher $\mathrm{CDW}$ concentrations, nor did it improve oAB production. Normal growth was only fully rescued when supplementing high amounts of phenylpyruvate $(\geq 5 \mathrm{mM})$ which would make the overall process highly uneconomical. Additionally, final oAB titers were still $49 \%$ lower than with the $\triangle \operatorname{tr} p D C$ strains, indicating a negative effect of the $p h e A$ deletion for the production of $\mathrm{OAB}$ in this organism. Thus, the most promising strain engineered for the production of $\mathrm{oAB}$ is $P$. putida $\triangle \operatorname{trpDC}$ pSEVA234_aroG $G^{D 146 N} \_\operatorname{trp} E^{S 40 F} G$ as it reached high titers of $\mathrm{OAB}$ and showed reduced sensitivity to tryptophan.

Dehydroshikimate, a metabolic intermediate of the shikimate pathway and thus a precursor of $\mathrm{OAB}$, accumulated as a by-product in all strains engineered for $\mathrm{OAB}$ production in shake flasks, indicating shikimate dehydrogenase as a likely bottleneck (Figure 3). This hypothesis is also supported by the transcriptome data sets of Wierckx et al. (2009) and Verhoef et al. (2010) showing upregulated 3-dehydroquinate and dehydroshikimate genes in the analyzed phenol and p-hydroxybenzoate production strains obtained by a fluoroanalog mutant screening.

\section{Production of OAB in Controlled Bioreactors}

The potential of $P$. putida $\triangle \operatorname{trpDC}$ pSEVA234_aroG $G^{D 146 N}$ $\operatorname{trp} E^{S 40 F} G$ to produce oAB was further assessed in tryptophanlimited fed batch cultures to circumvent the observed inhibition by tryptophan and maximize final oAB titers. A glucose-totryptophan molar ratio of 400:1 was estimated for biomass growth alone based on the initial shake flask experiments. Therefore, two different feeding approaches with a molar ratio of glucose to tryptophan of 1,000:1 and 2,000:1 were used to ensure a tryptophan limitation without excessive accumulation of glucose or its derivatives. Under these conditions a maximal titer of $1.54 \pm 0.3 \mathrm{~g} \mathrm{~L}^{-1} \mathrm{oAB}$ was reached from glucose as sole carbon source using the 2,000:1 feed (Figure 4). The higher ratio of glucose to tryptophan led to a more severe growth limitation, with CDW increasing only marginally during the production of oAB. In contrast, the 1,000:1 feed enabled more biomass growth at the cost of $\mathrm{OAB}$ production, leading to a final product titer of $1.0 \pm 0.07 \mathrm{~g} \mathrm{~L}^{-1}$. The product per substrate yield (based on consumed carbon source) for both conditions is relatively similar at $3.6 \pm 0.5 \%(\mathrm{~g} / \mathrm{g})$ for the $1,000: 1$ feed and $3.5 \pm 0.5 \%(\mathrm{~g} / \mathrm{g})$ for the 2,000:1 feed. oAB levels increased fairly linearly until the production stopped abruptly. Since the level of oAB produced is well below growth-inhibiting concentrations for $P$. putida (data not shown), oAB production is most likely stopped due to product inhibition, a known phenomenon for the production of aromatics (Gibson and Pittard, 1968; Wierckx et al., 2008; Rodriguez et al., 2014). This product inhibition likely takes place at the level of the anthranilate synthase. Indeed, the anthranilate synthase complex of other organisms is already inhibited by $\mathrm{OAB}$ concentrations in the micromolar range (Cordaro et al., 1968; Henderson et al., 1970; Francis et al., 1978). The oAB titers obtained with $P$. putida KT2440 in this study are about 10 -fold lower than those achieved by Balderas-Hernandez et al. (2009). The difference can most likely be attributed to the supplementation of $30 \mathrm{~g} / \mathrm{L}$ yeast extract by these researchers, 
which can provide $\mathrm{o} A \mathrm{~B}$ precursors and increases the general stress tolerance of microorganisms. This apparent positive effect of yeast extract on $\mathrm{OAB}$ production should be further investigated in order to elucidate the responsible components.

In the initial batch phase, the $50 \mathrm{mM}$ glucose were entirely consumed for the production of biomass. Tryptophan limiting conditions were confirmed by HPLC analysis throughout the fermentation $(<0.1 \mathrm{mM})$. Carbon source, either as glucose or as gluconate and 2-ketogluconate, were constantly present during the feed phase at total concentrations between 0.4 and $8.6 \mathrm{~g} \mathrm{~L}^{-1}$. In some fermenters, a prolonged incubation led to a decrease of $\mathrm{o} A \mathrm{~B}$ concentrations over time. Possibly, polymerization of $\mathrm{oAB}$ and/or its conversion products occurred.

\section{CONCLUSION}

Microbial production of $\mathrm{OAB}$ under industrial relevant conditions from glucose as sole carbon source was achieved in P. putida KT2440 via the biosynthesis pathway of aromatic amino acids. A strong connection between a tryptophan limitation and $\mathrm{OAB}$ production was observed even with strains bearing feedback insensitive overexpression constructs of $\operatorname{aro} G^{D 146 N}$ and $\operatorname{trp} E^{S 40 F} G$. Under tryptophan limiting fed-batch conditions, a maximum titer of $1.54 \pm 0.3 \mathrm{~g} \mathrm{~L}^{-1} \mathrm{oAB}$ was achieved with

\section{REFERENCES}

Albermann, C., Weiner, M., Trondle, J., Weuster-Botz, D., and Sprenger, G. A. (2014). Utilization of organophosphate:phosphate antiporter for isotopelabeling experiments in E. coli. FEMS Microbiol. Lett. 361, 52-61. doi: 10.1111/1574-6968.12612

Arias-Barrau, E., Olivera, E. R., Luengo, J. M., Fernandez, C., Galan, B., Garcia, J. L., et al. (2004). The homogentisate pathway: a central catabolic pathway involved in the degradation of L-phenylalanine, L-tyrosine, and 3hydroxyphenylacetate in Pseudomonas putida. J. Bacteriol. 186, 5062-5077. doi: 10.1128/JB.186.15.5062-5077.2004

Askham, L. R. (1992). "Efficacy of methyl anthranilate as a bird repellent on cherries, blueberries and grapes," in Proceeding of the 15th Vertebrate Pest Conference, eds J. E. Borrecco and R. E. Marsh (Davis, CA: University of California), 137-141.

Averesch, N. J. H., and Krömer, J. O. (2014). Tailoring strain construction strategies for muconic acid production in S. cerevisiae and E. coli. Metab. Eng. Commun. 1, 19-28. doi: 10.1016/j.meteno.2014.09.001

Bagdasarian, M., Lurz, R., Ruckert, B., Franklin, F. C., Bagdasarian, M. M., Frey, J., et al. (1981). Specific-purpose plasmid cloning vectors. II. Broad host range, high copy number, RSF1010-derived vectors, and a host-vector system for gene cloning in Pseudomonas. Gene 16, 237-247. doi: 10.1016/0378-1119(81)9 0080-9

Bahia, M. S., Gunda, S. K., Gade, S. R., Mahmood, S., Muttineni, R., and Silakari, O. (2011). Anthranilate derivatives as TACE inhibitors: docking based CoMFA and CoMSIA analyses. J. Mol. Model. 17, 9-19. doi: 10.1007/s00894-010-0 695-7

Balderas-Hernandez, V. E., Sabido-Ramos, A., Silva, P., Cabrera-Valladares, N., Hernandez-Chavez, G., Baez-Viveros, J. L., et al. (2009). Metabolic engineering for improving anthranilate synthesis from glucose in Escherichia coli. Microb. Cell Fact. 8:19. doi: 10.1186/1475-2859-8-19

Balderas-Hernandez, V. E., Trevino-Quintanilla, L. G., Hernandez-Chavez, G., Martinez, A., Bolivar, F., and Gosset, G. (2014). Catechol biosynthesis from glucose in Escherichia coli anthranilate-overproducer strains by heterologous expression of anthranilate 1,2-dioxygenase from Pseudomonas aeruginosa PAO1. Microb. Cell Fact. 13:136. doi: 10.1186/s12934-014-0136-x
P. putida KT2440 $\triangle \operatorname{trpDC}$ pSEVA234_aroG ${ }^{D 146 N} \_\operatorname{trp} E^{S 40 F} G$. This final achieved concentration is in the same range as other aromatics produced by P. putida strains (Nijkamp et al., 2005, 2007; Verhoef et al., 2007); although the titer is lower than that of previously published works with E. coli (Balderas-Hernandez et al., 2009). However, the supplementation with yeast extract was avoided and $\mathrm{OAB}$ was only produced from glucose. In addition, to ensure long term strain stability, one of the main requirements in industrial biotechnology, a stable and markerless deletion of the genes responsible for the conversion of $\mathrm{OAB}$ towards tryptophan $(\operatorname{trpDC})$ was used. Nevertheless, the oAB titer and yield reached with $P$. putida KT2440 are below those which are required to realize an industrial feasible process. Further improvement is required, e.g., by more in-depth metabolic engineering (e.g., overexpression of tkt: Balderas-Hernandez et al., 2009) as well as by in situ product removal to alleviate product inhibition. Further research on the mechanism of product inhibition of $\mathrm{oAB}$ production could also lead to additional metabolic engineering targets to improve microbial $\mathrm{oAB}$ production.

\section{ACKNOWLEDGMENT}

NW was supported by the German Research Foundation through the Emmy Noether project WI 4255/1-1.

Berg, C. (2009). Treatment of Aqueous Liquids and the Preparation of Anthranilic Acid. US 20090171116 A1.

Blank, L. M., Ionidis, G., Ebert, B. E., Buhler, B., and Schmid, A. (2008). Metabolic response of Pseudomonas putida during redox biocatalysis in the presence of a second octanol phase. FEBS J. 275, 5173-5190. doi: 10.1111/j.17424658.2008.06648.x

Bongaerts, J., Kramer, M., Muller, U., Raeven, L., and Wubbolts, M. (2001). Metabolic engineering for microbial production of aromatic amino acids and derived compounds. Metab. Eng. 3, 289-300. doi: 10.1006/mben.20 01.0196

Chambers, A. H., Evans, S. A., and Folta, K. M. (2013). Methyl anthranilate and gamma-decalactone inhibit strawberry pathogen growth and achene Germination. J. Agric. Food Chem. 61, 12625-12633. doi: 10.1021/jf40 4255 a

Chavarria, M., Nikel, P. I., Perez-Pantoja, D., and De Lorenzo, V. (2013). The Entner-Doudoroff pathway empowers Pseudomonas putida KT2440 with a high tolerance to oxidative stress. Environ. Microbiol. 15, 1772-1785. doi: $10.1111 / 1462-2920.12069$

Choi, K. H., Kumar, A., and Schweizer, H. P. (2006). A 10-min method for preparation of highly electrocompetent Pseudomonas aeruginosa cells: application for DNA fragment transfer between chromosomes and plasmid transformation. J. Microbiol. Methods 64, 391-397. doi: 10.1016/j.mimet.2005.06.001

Cordaro, J. C., Levy, H. R., and Balbinder, E. (1968). Product inhibition of anthranilate synthetase in Salmonella typhimurium. Biochem. Biophys. Res. Commun. 33, 183-189. doi: 10.1016/0006-291X(68)90765-1

Ditta, G., Stanfield, S., Corbin, D., and Helinski, D. R. (1980). Broad host range DNA cloning system for gram-negative bacteria: construction of a gene bank of Rhizobium meliloti. Proc. Natl. Acad. Sci. U.S.A. 77, 7347-7351. doi: 10.1073/pnas.77.12.7347

Dominguez-Cuevas, P., Gonzalez-Pastor, J. E., Marques, S., Ramos, J. L., and De Lorenzo, V. (2006). Transcriptional tradeoff between metabolic and stressresponse programs in Pseudomonas putida KT2440 cells exposed to toluene. J. Biol. Chem. 281, 11981-11991. doi: 10.1074/jbc.M509848200

Figurski, D. H., Meyer, R. J., and Helinski, D. R. (1979). Suppression of ColE1 replication properties by the Inc P-1 plasmid $\mathrm{RK} 2$ in hybrid 
plasmids constructed in vitro. J. Mol. Biol. 133, 295-318. doi: 10.1016/00222836(79)90395-4

Francis, M. M., Vining, L. C., and Westlake, D. W. (1978). Characterization and regulation of anthranilate synthetase from a chloramphenicol-producing streptomycete. J. Bacteriol. 134, 10-16.

Gao, X., Jiang, W., Jimenez-Oses, G., Choi, M. S., Houk, K. N., Tang, Y., et al. (2013). An iterative, bimodular nonribosomal peptide synthetase that converts anthranilate and tryptophan into tetracyclic asperlicins. Chem. Biol. 20, 870878. doi: 10.1016/j.chembiol.2013.04.019

Gibson, F., and Pittard, J. (1968). Pathways of biosynthesis of aromatic amino acids and vitamins and their control in microorganisms. Bacteriol. Rev. 32, 465-492.

Hallsworth, J. E., Heim, S., and Timmis, K. N. (2003). Chaotropic solutes cause water stress in Pseudomonas putida. Environ. Microbiol. 5, 1270-1280. doi: 10.1111/j.1462-2920.2003.00519.x

Hanahan, D. (1985). “Techniques for transformation of E. coli," in DNA Cloning: A Practical Approach, ed. D. M. Glover (Oxford: IRL Press), 109-135.

Haynes, S. W., Gao, X., Tang, Y., and Walsh, C. T. (2012). Assembly of asperlicin peptidyl alkaloids from anthranilate and tryptophan: a two-enzyme pathway generates heptacyclic scaffold complexity in asperlicin E. J. Am. Chem. Soc. 134, 17444-17447. doi: 10.1021/ja308371z

Heipieper, H. J., and de Bont, J. A. M. (1994). Adaptation of Pseudomonas putida S12 to ethanol and toluene at the level of fatty acid composition of membranes. Appl. Environ. Microbiol. 60, 4440-4444.

Henderson, E. J., Nagano, H., Zalkin, H., and Hwang, L. H. (1970). The anthranilate synthetase-anthranilate 5-phosphoribosylpyrophosphate phosphoribosyltransferase aggregate. Purification of the aggregate and regulatory properties of anthranilate synthetase. J. Biol. Chem. 245, 1416-1423.

Horton, R. M. (1995). PCR-mediated recombination and mutagenesis. SOEing together tailor-made genes. Mol. Biotechnol. 3, 93-99. doi: 10.1007/BF027 89105

Ikeda, M. (2003). Amino acid production processes. Adv. Biochem. Eng. Biotechnol. $79,1-35$.

Jaeger, G., Magnus, J., Moussa, A. S., Olf, G., Lolli, G., Behnken, S., et al. (2015). Recombinant Strain Producing O-Aminobenzoate and Fermentative Production of Aniline from Renewable Resources Via 2-Aminobenzoic Acid. Google Patents 2015124687.

Kikuchi, Y., Tsujimoto, K., and Kurahashi, O. (1997). Mutational analysis of the feedback sites of phenylalanine-sensitive 3-deoxy-D-arabino-heptulosonate-7phosphate synthase of Escherichia coli. Appl. Environ. Microbiol. 63, 761-762.

Klipper, G., and Gripper, J. (1981). Continuous Preparation of Anthranilic Acid. US 4276433 A.

Kramer, M., Bongaerts, J., Bovenberg, R., Kremer, S., Muller, U., Orf, S., et al. (2003). Metabolic engineering for microbial production of shikimic acid. Metab. Eng. 5, 277-283. doi: 10.1016/j.ymben.2003.09.001

Kwak, J. H., Hong, K. W., Lee, S. H., Hong, J. H., and Lee, S. Y. (1999). Identification of amino acid residues involved in feedback inhibition of the anthranilate synthase in Escherichia coli. J. Biochem. Mol. Biol. 32, 20-24.

Leuchtenberger, W., Huthmacher, K., and Drauz, K. (2005). Biotechnological production of amino acids and derivatives: current status and prospects. Appl. Microbiol. Biotechnol. 69, 1-8. doi: 10.1007/s00253-005-0155-y

Loque, D., and Weniger, A. G. E. (2013). Host Cells and Methods for Producing Cinnamoyl Anthranilate and Analogs Thereof. US 2013007 8683, A1.

Martinez-Garcia, E., and de Lorenzo, V. (2011). Engineering multiple genomic deletions in Gram-negative bacteria: analysis of the multi-resistant antibiotic profile of Pseudomonas putida KT2440. Environ. Microbiol. 13, 2702-2716. doi: 10.1111/j.1462-2920.2011.02538.x

Maurer, R., and Crawford, I. P. (1971). New regulatory mutation affecting some of the tryptophan genes in Pseudomonas putida. J. Bacteriol. 106, 331-338.

Molina-Henares, M. A., Garcia-Salamanca, A., Molina-Henares, A. J., De La Torre, J., Herrera, M. C., Ramos, J. L., et al. (2009). Functional analysis of aromatic biosynthetic pathways in Pseudomonas putida KT2440. Microb. Biotechnol. 2, 91-100. doi: 10.1111/j.1751-7915.2008.00062.x

Nijkamp, K., Van Luijk, N., De Bont, J. A., and Wery, J. (2005). The solventtolerant Pseudomonas putida S12 as host for the production of cinnamic acid from glucose. Appl. Microbiol. Biotechnol. 69, 170-177.

Nijkamp, K., Westerhof, R. G., Ballerstedt, H., De Bont, J. A., and Wery, J. (2007). Optimization of the solvent-tolerant Pseudomonas putida S12 as host for the production of p-coumarate from glucose. Appl. Microbiol. Biotechnol. 74, 617-624. doi: 10.1007/s00253-006-0703-0

Pittard, J., and Yang, J. (2008). Biosynthesis of the aromatic amino acids. EcoSal Plus 1, 1-39. doi: 10.1128/ecosalplus.3.6.1.8

Poblete-Castro, I., Becker, J., Dohnt, K., Dos Santos, V. M., and Wittmann, C. (2012). Industrial biotechnology of Pseudomonas putida and related species. Appl. Microbiol. Biotechnol. 93, 2279-2290. doi: 10.1007/s00253-012-3 928-0

Raffensperger, S. P., and Vogt, R. D. (1961). Stabilization of Grape Flavored Soft Drink Mixes Containing Methyl Anthranilate. US 3005715 A.

Rodriguez, A., Martinez, J. A., Flores, N., Escalante, A., Gosset, G., and Bolivar, F. (2014). Engineering Escherichia coli to overproduce aromatic amino acids and derived compounds. Microb. Cell. Fact. 13:126. doi: 10.1186/s12934-014-0 $126-\mathrm{z}$

Shafiq, M., Zia-Ur-Rehman, M., Khan, I. U., Arshad, M. N., and Khan, S. A. (2011). Synthesis of novel anti-bacterial 2,1-benzothiazine 2,2-dioxides derived from methyl anthranilate. J. Chil. Chem. Soc. 56, 527-531. doi: 10.4067/S071797072011000100001

Silva-Rocha, R., Martinez-Garcia, E., Calles, B., Chavarria, M., ArceRodriguez, A., De Las Heras, A., et al. (2013). The standard european vector architecture (SEVA): a coherent platform for the analysis and deployment of complex prokaryotic phenotypes. Nucleic Acids Res. 41, D666-D675. doi: 10.1093/nar/gks1119

Sun, X., Lin, Y., Huang, Q., Yuan, Q., and Yan, Y. (2013). A novel muconic acid biosynthesis approach by shunting tryptophan biosynthesis via anthranilate. Appl. Environ. Microbiol. 79, 4024-4030. doi: 10.1128/AEM.00859-13

Tiso, T., Wierckx, N., and Blank, L. M. (2014). Non-pathogenic Pseudomonas as Platform for Industrial Biocatalysis. Singapore: Pan Stanford Publishing.

Verhoef, S., Ballerstedt, H., Volkers, R. J. M., De Winde, J. H., and Ruijssenaars, H. J. (2010). Comparative transcriptomics and proteomics of p-hydroxybenzoate producing Pseudomonas putida S12: novel responses and implications for strain improvement. Appl. Environ. Microbiol. 87, 679-690. doi: $10.1007 / \mathrm{s} 00253-010-2626-\mathrm{Z}$

Verhoef, S., Ruijssenaars, H. J., De Bont, J. A., and Wery, J. (2007). Bioproduction of p-hydroxybenzoate from renewable feedstock by solvent-tolerant Pseudomonas putida S12. J. Biotechnol. 132, 49-56. doi: 10.1016/j.jbiotec.2007.08.031

Verhoef, S., Wierckx, N., Westerhof, R. G., De Winde, J. H., and Ruijssenaars, H. J. (2009). Bioproduction of p-hydroxystyrene from glucose by the solvent-tolerant bacterium Pseudomonas putida S12 in a two-phase water-decanol fermentation. Appl. Environ. Microbiol. 75, 931-936. doi: 10.1128/AEM.02186-08

Walsh, C. T., Haynes, S. W., Ames, B. D., Gao, X., and Tang, Y. (2013). Short pathways to complexity generation: fungal peptidyl alkaloid multicyclic scaffolds from anthranilate building blocks. ACS Chem. Biol. 8, 1366-1382. doi: $10.1021 / \mathrm{cb} 4001684$

Wang, H. H., Zhou, X. R., Liu, Q., and Chen, G. Q. (2011). Biosynthesis of polyhydroxyalkanoate homopolymers by Pseudomonas putida. Appl. Microbiol. Biotechnol. 89, 1497-1507. doi: 10.1007/s00253-010-2964-x

Wierckx, N. J., Ballerstedt, H., De Bont, J. A., and Wery, J. (2005). Engineering of solvent-tolerant Pseudomonas putida S12 for bioproduction of phenol from glucose. Appl. Environ. Microbiol. 71, 8221-8227. doi: 10.1128/AEM.71.12.8221-8227.2005

Wierckx, N. J. P., Ballerstedt, H., De Bont, J. A. M., De Winde, J. H., Ruijssenaars, H. J., and Wery, J. (2008). Transcriptome analysis of a phenol-producing Pseudomonas putida S12 construct: genetic and physiological basis for improved production. J. Bacteriol. 190, 2822-2830. doi: 10.1128/JB.01379-07

Wierckx, N., Ruijssenaars, H. J., De Winde, J. H., Schmid, A., and Blank, L. M. (2009). Metabolic flux analysis of a phenol producing mutant of Pseudomonas putida S12: verification and complementation of hypotheses derived from transcriptomics. J. Biotechnol. 143, 124-129. doi: 10.1016/j.jbiotec.2009.0 6.023

Wiklund, P., and Bergman, J. (2006). The chemistry of anthranilic acid. Curr. Organ. Synth. 3, 379-402. doi: 10.2174/1570179067779 34926

Wittgens, A., Tiso, T., Arndt, T. T., Wenk, P., Hemmerich, J., Muller, C., et al. (2011). Growth independent rhamnolipid production from glucose using the non-pathogenic Pseudomonas putida KT2440. Microb. Cell Fact. 10:80. doi: $10.1186 / 1475-2859-10-80$ 
Yadav, G. D., and Krishnan, M. S. (1998). An ecofriendly catalytic route for the preparation of perfumery grade methyl anthranilate from anthranilic acid and methanol. Organ. Process. Res. Dev. 2, 86-95. doi: 10.1021/op980074j

Zhao, Z. J., Zou, C., Zhu, Y. X., Dai, J., Chen, S., Wu, D., et al. (2011). Development of L-tryptophan production strains by defined genetic modification in Escherichia coli. J. Ind. Microbiol. Biotechnol. 38, 1921-1929. doi: 10.1007/s10295-011-0978-8

Zobel, S., Benedetti, I., Eisenbach, L., De Lorenzo, V., Wierckx, N., and Blank, L. M. (2015). A Tn7-based device for calibrated heterologous gene expression in Pseudomonas putida. ACS Synth. Biol. doi: 10.1021/acssynbio.5b00058 [Epub ahead of print].
Conflict of Interest Statement: The authors declare that the research was conducted in the absence of any commercial or financial relationships that could be construed as a potential conflict of interest.

Copyright (c) 2015 Kuepper, Dickler, Biggel, Behnken, Jäger, Wierckx and Blank. This is an open-access article distributed under the terms of the Creative Commons Attribution License (CC BY). The use, distribution or reproduction in other forums is permitted, provided the original author(s) or licensor are credited and that the original publication in this journal is cited, in accordance with accepted academic practice. No use, distribution or reproduction is permitted which does not comply with these terms. 